\title{
Evaluation of Award Factors for Students' Competitions Based on AHP
}

\author{
Keyu Bao \\ School of Management \\ Capital Normal University \\ Beijing China
}

\author{
Jingjie Liu \\ School of Management \\ Capital Normal University \\ Beijing China
}

\author{
Yan Peng* \\ School of Management \\ Capital Normal University \\ Beijing China
}

\begin{abstract}
In recent years, a number of high-level science and technology competitions for college students have gradually emerged, and some contests with wide spread participation, strong influence, and species diversity have gradually formed. While facing a variety of choices and opportunities, students are also met with puzzles of which one is more beneficial to them. In this paper, based on the data recorded during 1989-2017 from "The Challenge Cup", 2013-2015 from "The Share Cup", and 2011-2017 from "The HUAWEI Cup", descriptive statistics is made at first to characterize the overall situation data. Then the competition's winning factors are analyzed. Secondly, with the design of the questionnaire, preliminarily set of relevant factors is done. The competency model is used to model the characteristics of the participating and award-winning students, and the characteristics of the entries are modeled by the analytic hierarchy process. Finally, based on the above research, by putting forward the ways and methods of improving college students winning probability, and gives relevant suggestions, I hope that this research can attract more students to participate in science and technology competition, stimulate innovation potential competitors, and enhance the competition effect.
\end{abstract}

Keywords-science and technology competitions; awardwinning factors; competency model; the analytic hierarchy process

\section{INTRODUCTION}

In the 21st century of rapid development, science and technology play an increasingly important role in social development. In order to better adapt to the development of the times, more and more institutions and universities have begun to pay attention to the cultivation of scientific and technological innovation ability of college students. A large number of college students' science and technology competition are appeared. This development is conducive to students to develop innovative thinking, stimulate the enthusiasm and interest of active learning, and cultivate team awareness and organizational coordination.

However, while there are many competition choices and

This work is supported by Project of Science Innovation Platform of Beijing Education Commission (No.025185305000/035) opportunities, college students also face the confusion of which competition is suitable for them and how to choose the competition. In order to solve this problem, an in-depth analysis of the competition and award data of the technology competition in the past ten years were implemented by this paper: Firstly, 18 competition awarding factors are obtained by the analytic hierarchy process, such as the participant knowledge level, the behavioral characteristics and the preference of the contestants. Secondly, the importance of each factor to the award is analyzed by competency model. Finally, the conclusions of the research work will play an active role in promoting the talents of science and technology innovation in the process of completing the works.

\section{LITERATURE REVIEW}

\section{A. Research Background}

Since the first "Challenge Cup" held in 1989, after decades of development, China has now basically formed a competition framework with a wide range of entries and rich contents. In 2008, Tao Gao pointed out that "The Challenge Cup" competition improved the scientific knowledge and skills of the vast majority of participants [1]. In 2013, Wei Fang and Xi Wang proposed that in order to better adapt to the development of the times, more and more institutions and universities began to pay attention to the cultivation of college students' scientific and technological innovation ability [2]. In 2010, Yuhong Guo, Haiping Xue, and Fei Wang proposed that the science and technology competition aims to improve the enthusiasm and scientific quality of the participants and promote the enthusiasm and initiative of students [3]. Compared with domestic, university academic competitions have a longer history in other countries, and have formed a stable model, most of which are large in scale and high in level. Among them, " Imagine Cup " and " ACM-ICPC" are very famous. In 2012, Ruisan Chen and Qingyan Wu proposed that science and technology competitions aboard is more concise and reasonable in procedure than the domestic. In addition, the utilitarian factors such as spiritual honor, material interest and employment promotion in foreign competitions are more 
obvious than domestic ones, which can stimulate the creative motives of the contestants [4].

\section{B. AHP Method}

Analytic Hierarchy Process (AHP) is a multi-objective decision analysis method that combines qualitative and quantitative analysis methods. It was proposed by American operations researcher T.L. Saaty in the early 1970s. The main idea is to decompose complex problems into several levels and several factors, then compare and calculate the importance between the two indicators, finally obtain the weight of different schemes and provides the basis for the choice of the best solution. The method has the advantages of system, flexibility and simplicity.

In corporate project decisions, AHP was used to prioritize projects in the company's portfolio by Pablo Aragonés-Beltrán [5]. In terms of industrial transportation decision-making, the analytic hierarchy process was used to determine the optimal operation choice for the mode of transportation by Jiang Liu [6] and others. In the article "Analytic Hierarchy Analysis of Mathematical Modeling", the analytic hierarchy process was used to choose a optimal solution of selecting the 1-5 method for the work scheduling of the crane and smelting furnace in the 1995 National College Student Mathematical Model Competition by Huayi Chen [7]. In the research of competition evaluation program, a correct result was obtained in the evaluation of the outstanding works of the Challenge Cup Entrepreneurship Competition [8] by Chao Chang and others. In order to reach this result, the scores of the participating teams were analyzed in depth based on the design of the evaluation index system of the business plan competition, using AHP analytic method to determine the index weight, with the help of the experts' evaluation information comprehensively evaluated by the gray cluster analysis method.

\section{ACADEMIC CONTENTS DATA ANALYSIS}

\section{A. Data Sources}

The data source of this paper is divided into three parts.

One is the information published on the "The Challenge Cup” petition data and award data.

Second, through cooperation with the organizers of the "The Share Cup", "The HUAWEI Cup" and "Boer Cup", the organizers provided detailed entry data to ensure the authenticity of the data. It includes data on 18 entries in the above three major competitions, including entry information, participant information, award information, and review comments. For this part of the data, the research group is only used for the research of this topic and may not be used for any other purposes.

Third, the students and graduate students of different universities in different provinces and cities in China are surveyed, and the data collected by the questionnaires are distributed nationwide through the network.

\section{B. Selection of several Influencing Factors}

Based on the data of competition and award of "The Challenge Cup", "The HUAWEI Cup" and "The Share Cup" from 1989 to 2017, the research group analyzed the general trend of the competition the evaluation principle and analyzed the factors of winning the competition. First of all, the relevant subjects of college students' science and technology competition are divided into two aspects: contestants and entries. Secondly, the two aspects are studied in detail. According to the participants, mainly from the knowledge, attitude, skill embodiment, personal quality, external factors several dimensions to analyze, and attitude, skills embodiment, personal quality can be summed up into the contestants. "Behavioral characteristics", "knowledge" is measured by "knowledge level", and there are "faculties", "majors" and "grades". Based on the above analysis, the following assumptions are proposed:

TABLE I. HYPOTHESIS

\begin{tabular}{|c|c|}
\hline Hypothesis & Description \\
\hline H1 & $\begin{array}{l}\text { the level of knowledge has a significant effect on the college } \\
\text { students participating in the awards. }\end{array}$ \\
\hline H1a & $\begin{array}{l}\text { colleges and universities have a significant impact on students } \\
\text { participating in the awards }\end{array}$ \\
\hline H1b & $\begin{array}{l}\text { professional has a significant impact on the award of } \\
\text { university students. }\end{array}$ \\
\hline $\mathrm{H} 1 \mathrm{c}$ & grade has a significant effect on college students' winning. \\
\hline $\mathrm{H} 2$ & $\begin{array}{l}\text { behavioral characteristics have a significant impact on } \\
\text { College students' Achievement }\end{array}$ \\
\hline $\mathrm{H} 2 \mathrm{a}$ & $\begin{array}{l}\text { Sense of responsibility has a significant impact on the } \\
\text { participation of college students in the competition }\end{array}$ \\
\hline $\mathrm{H} 2 \mathrm{~b}$ & $\begin{array}{l}\text { the attitude of competition has a significant influence on } \\
\text { college students' winning }\end{array}$ \\
\hline $\mathrm{H} 2 \mathrm{c}$ & $\begin{array}{l}\text { the ability of cooperation has significant influence on college } \\
\text { students' winning }\end{array}$ \\
\hline H3 & teacher guidance has a significant impact on college students \\
\hline $\mathrm{H} 4$ & $\begin{array}{l}\text { the tendency to choose the topic has a significant effect on the } \\
\text { college students }\end{array}$ \\
\hline H5 & $\begin{array}{l}\text { the feature of the work has significant influence on the } \\
\text { college students }\end{array}$ \\
\hline
\end{tabular}

The guidance teacher belongs to the external factor, has the function of "teacher guidance". Therefore, the hypothesis that H3: teacher guidance has a significant impact on college students. The contestants have a certain role in choosing the selected topics of the entries, so the "tendency to choose topics" also belongs to the subjective ideas of the contestants and the factors of competence and diathesis. The hypothesis H4 the tendency to choose the topic has a significant effect on the college students.

In the questionnaire survey, the Likert scale was used to design. The six factors that affect the winning work were summarized by performing precise semantic analysis combined the evaluation principle of winning entries of "The Challenge Cup", "Boer Cup" and "The Share Cup" in the past two years. The six factors are degree of completion, professionalism, innovation, promotion, display, conformity with the principles of the competition. According to these six dimensions, hypothesis $\mathrm{H} 5$ was advanced by the analytic hierarchy process. Hypothesis $\mathrm{H} 5$ is that the characteristics of the work have a significant impact on the winning of college students.

Based on the above analysis, a modified hypothesis model of competency model is established to explore the winning 
factors of university students' science and technology competition, as shown in Fig.1.

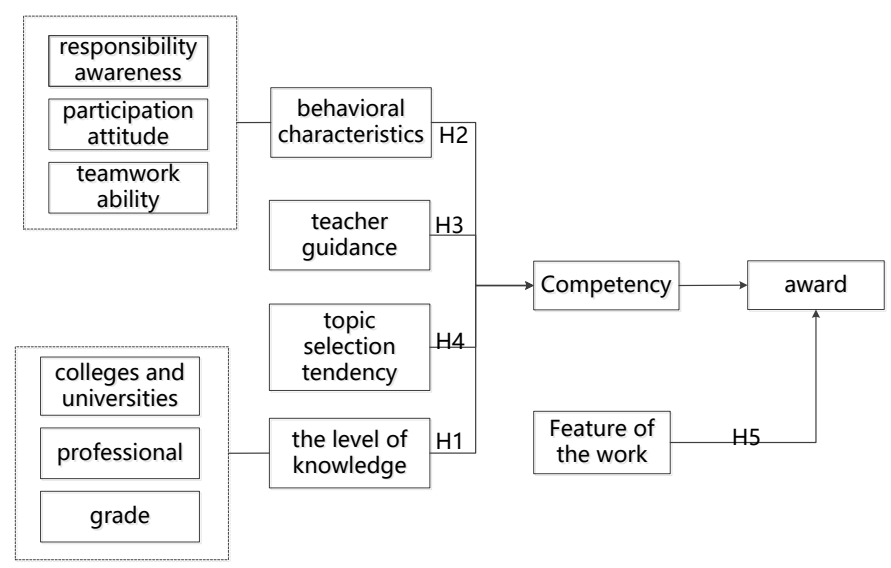

Fig. 1. Competency quality revision hypothesis model

\section{Winning Factors Analysis Based on AHP}

Based on the above analysis, the analytic hierarchy process was used to analysis "The Challenge Cup", "The Share Cup", "Huawei Cup" three competitions and winning data, Based on this, the award factors are attributed to the degree of completion, professionalism, innovation, promotion, display, and conformity with the principles of the competition. Through the analysis and comparison of these factors, the importance of the factors affecting the award is obtained. The above process is in line with the AHP analysis mode.

\section{RESULT ANALYSIS}

\section{A. Reliability Analysis}

In order to understand the reliability of the questionnaire, we analyzed the reliability of the questionnaire. The results show that the reliability coefficient of the total scale is $0.873>$ 0.8 , and the degree of confidence is high. The reliability of the subscale is also higher than 0.7 , which is credible and has certain research significance.

TABLE II. RELIABILITY ANALYSIS OF SUBSCALE

\begin{tabular}{|c|c|}
\hline Variable name & Alpha \\
\hline responsibility awareness & 0.851 \\
\hline participation attitude & 0.779 \\
\hline teamwork ability & 0.728 \\
\hline teacher guidance & 0.712 \\
\hline topic selection tendency & 0.788 \\
\hline Feature of the work & 0.873 \\
\hline
\end{tabular}

\section{B. Analysis of Students' Characteristics Based on Competency Model}

For the influence of students, majors, colleges, attitudes, and teacher guidance on the awards, the significance of the variance test $P$ values were $0.298,0.288,0.215,0.35$, and 0.62 , respectively, which were greater than 0.05 , which was considered to be the winner of the science and technology competition. There was no significant difference.

For the influence of the students' grade level, responsibility awareness, participation attitude, teamwork ability and topic selection tendency, the significance of the variance test $P$ value is $0.027,0.018,0.042,0.028$, respectively, less than 0.05 , which is considered to be the winner of the science and technology competition. There is a positive correlation.

\section{Analysis of the Characteristics of Entries Based on AHP}

\section{1) Establish a hierarchical model.}

Through consulting a large amount of literature, in-depth analysis of the winning factors affecting college students' science and technology competition, the problem is divided into three layers, namely the target layer, the criterion layer and the program layer. The target layer is the winning factor, and the criteria layer includes the degree of completion, professionalism, innovation, promotion, and display ability of the entries, and the degree of conformity with the competition principles. The program level is awarded and not awarded.

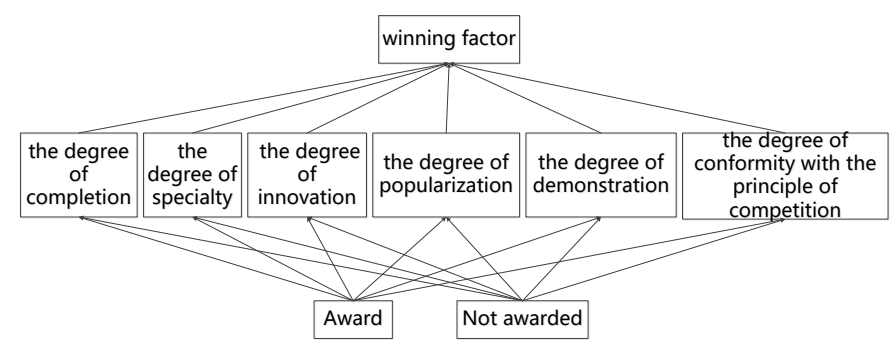

Fig. 2. Entry feature analysis model

\section{2) Construct judgment matrix.}

Through the evaluation of the students' self-winning works and the evaluation principles of the major science and technology competitions in the questionnaire, after the two indicators of the indicators in the criteria layer are compared, the judgment matrix A is constructed as shown in formula (1).

$$
\mathrm{A}=\left[\begin{array}{cccccc}
1 & 3 & 5 & \frac{1}{5} & 5 & 3 \\
\frac{1}{3} & 1 & 5 & \frac{1}{6} & 3 & \frac{1}{5} \\
\frac{1}{5} & \frac{1}{5} & 1 & \frac{1}{9} & 1 & \frac{1}{7} \\
5 & 6 & 9 & 1 & 9 & 3 \\
\frac{1}{5} & \frac{1}{3} & 1 & \frac{1}{9} & 1 & \frac{1}{7} \\
\frac{1}{3} & 5 & 7 & \frac{1}{3} & 7 & 1
\end{array}\right]
$$

3) Consistency test.

The Yaahp software is used to test the consistency of the judgment matrix. Through judgment, the test coefficient is $0.0948<0.10$. It is considered that the judgment matrix passes consistency test.

4) Determine the hierarchy and make decisions according to the sort.

To sum up, the order of importance is "degree of innovation" > "degree of conformity with competition 
principle" > "degree of completion" > "degree of professionalism" > "degree of demonstration" = "degree of extensibility", Available: the probability of winning is 0.802 2, the probability of not winning is 0.1978 .

\section{CONCLUSION}

Through the above detailed data and survey of college students' science and technology competition, the following conclusions were reached:

First, the selected topic of the award-winning works would better to connected to daily life and social hot issues, which have strong innovative and practical value. Meanwhile, those simple topics are easy to complete, but often are not highly innovative and cannot get a good award.

Second, the higher the subject and the principle of the competition, the easier it is to win the prize.

Third, the degree of completion of the work has a significant impact on the award: the higher the degree of completion, the greater the probability of winning.

Fourth, the gender, majors, and institutions of the contestants have no significant influence on the students' technology competition. However, an interesting conclusion is that the competition team with senior students and graduate students has a high proportion of awards and a high level of awards.

Fifth, the degree of exhibition and promotion of the entries have great influence on the award, which have the same status.

Sixth, the participants' sense of responsibility, teamwork and attitude have a significant impact on the winning of science and technology competition.

Seventh, according to the survey results, the teacher's guiding role has no significant impact on the student's award and the level of award. This deviates from the general perception. Obviously, students overemphasize their own values and ignore the teachers' contributions.

\section{SUGGESTION}

Based on above data analysis and questionnaire survey, we made several suggestions for the contest organizers and participating students.
First, the topic needs to be forward-looking and innovative. It is recommended to choose more practical topics related to daily life and social hot issues, and be sure to pay attention to the innovation degree of the works. It's best to fit your major to maximize your strengths. Then, it is possible to maximize the display ability and promotion of the work. Besides, students should choose a competition that suits them. choosing a competition that suits their own characteristics can fully advantage their own and increase the chance of winning. In addition,students from all grades participating in the same competition are encouraged. The lower grade students can participate in the senior team's main team. Last but not least, it is recommended to select the instructors who are experienced in guiding team and whose research direction is similar to the participating subjects.

\section{REFERENCES}

[1] Tao Gao. Effects of 'the Challenging-Cup Competition' on the Scientific Literacy of Undergraduate Students in Biological Sciences[D]. Guangzhou University, 2008,In Chinese.

[2] Wei Fang, Xi Wang. Investigation and study on the factors influencing the achievements of college students' scientific and technological innovation competition. Beijing: Beijing Education (Medical Education), vol. 03,2013,pp. 73-75, In Chinese.

[3] Yuhong Guo, Haiping Xue, Fei Wang. Review of Foreign Youth Sci tech Competitions[J].Journal of Shanghai Educational Research, vol. 9,2010,pp.32-36,In Chinese.

[4] Ruisan Chen, Qingyan Wu. Influence of Domestic and Foreign Scientific and Technological Competitions on College Students' Motivation[J].China Science and Technology Information, vol. 07,2013,pp.208- 209,In Chinese.

[5] Pablo Aragonés-Beltrán,Fidel Chaparro-González, Juan-Pascual PastorFerrando,Andrea Pla-Rubio. An AHP (Analytic Hierarchy Process)/ANP (Analytic Network Process)-based multi-criteria decision approach for the selection of solar-thermal power plant investment projects[J]. Energy,2014,66:.

[6] Jiang Liu. The Choice of Enterprise Transportation Mode Based on Analytic Hierarchy Process[J]. University of International Business and Economics, 2006,In Chinese.

[7] Huayi Chen. Analytic Hierarchy Pocess of Mathematical Modeling [J]. Journal of Lanzhou University of Technology,1997,(03):93-98,In Chinese.

[8] Chao Chang, Long Ming. "The Challenge Cup" business plan competition review program [J]. China Economist,2011,(08):121-124,In Chinese. 